\title{
An Analysis of the Playing Skills of Chopin's The Second Scherzo in B-flat Minor
}

\author{
Yu Liu \\ Xi'an Shiyou University, Xi'an Shaanxi, 710065, China
}

Keywords: Chopin; Scherzo; playing skills

\begin{abstract}
The Second Scherzo in B-flat Minor is the most unique one of Chopin's four piano scherzos with a huge and complex musical structure, a unique piano texture and a bold and novel use of harmony, so it is difficult to play. Based on the author's own performing experience, this paper expounds the playing skills of The Second Scherzo in B-flat Minor.
\end{abstract}

\section{Introduction}

The Second Scherzo in B-flat Minor is the most famous one of Chopin's four piano scherzos. It has a huge and complex musical structure, a unique piano texture and a bold and novel use of harmony, plus obvious visual components, which undoubtedly makes the song very difficult to play, thus deterring many music lovers. Also, the song has left a great space for performers' derivative creation. The wonderful performances of many pianists has presented completely diverse styles and made it difficult for beginners to choose. In view of this, it is very necessary to analyze in-depth and detailed playing skills in The Second Scherzo in B-flat Minor.

\section{Playing Skills in the Presentation Section}

The presentation section(sotto voce)in The Second Scherzo in B-flat Minor(1-264 bars), has a speed marked Presto. The performers must demonstrate a rapid speed and a clear rhythm, and form a subjective impression of speed and sound to the audience. The first theme (1-64 bars) consists of two main factors. One is doubtful and the other is firm and decisive. Dealing with the relationship between the two is the key to playing the first theme. The first three subsections of the music are like the composer's questions, which show his hesitating and doubting inner feelings. The performers need to use sotto voce (whisper) to play triplet chords with small detailed sounds. Next, Section 5 of the music gives the questioner a definitive answer with a clear octave of chords. The hit of the "ff" contrasts sharply with the strength of the previous triplet chords and creates a compelling dramatic effect. At this point, the performer must pay attention to the strength of the grasp. When dealing with the melody of octaves, one should strain the wrists, and be decisive, firm, and focused. In particular, attention should be paid to the clearness and fullness of the chords. Too choppy chords and excessive pauses are common mistakes for beginners, which should be avoided. (See Score Example 1)

Immediately after the wonderful beginning, from the 49th bar, the short and bright phrase is like a waterfall falling from a height, smooth and gorgeous. In this part, the music is mainly composed of fast-moving sounds, so special attention must be paid to the cooperation of the two hands, the quarter-note in the left hand be stable and strong, and the contrast in the intensity be sharp and strong; the eighth-note in the right hand should be fast and warm, and the music should be clean and smooth to avoid blunt and cold impressions. (Score Example 1) 

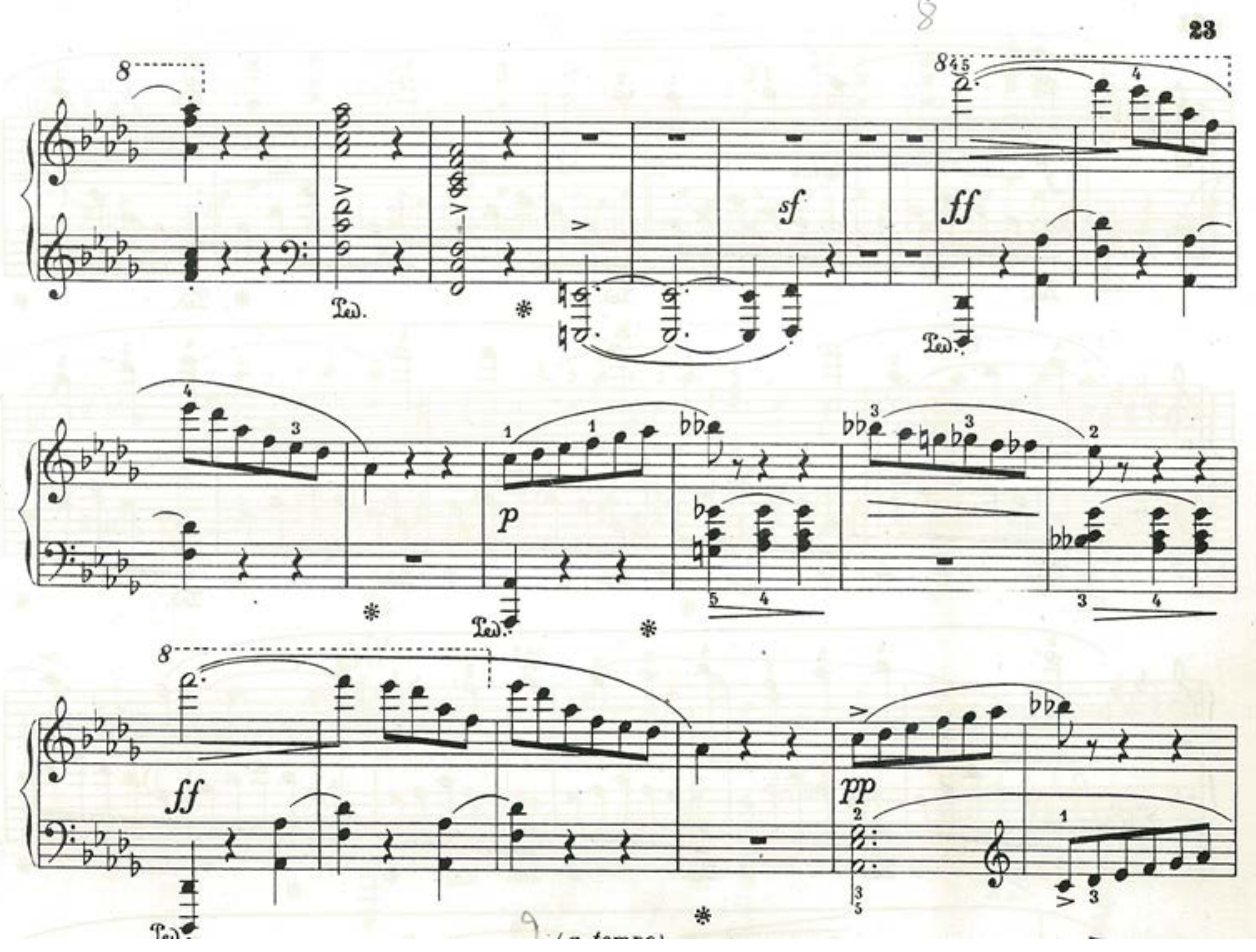

Score Example 1 41-63 bars

In the last two subsections of the first theme, the poco rit mark suggests that the level of player's strength must be planned properly; the right hand should be dexterous, the downside of the left hand chromatic scale should be soft, and the convergence between the two should be smooth and natural,

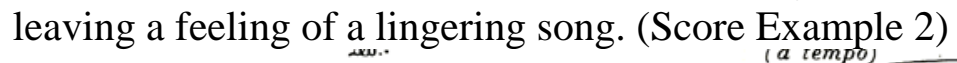
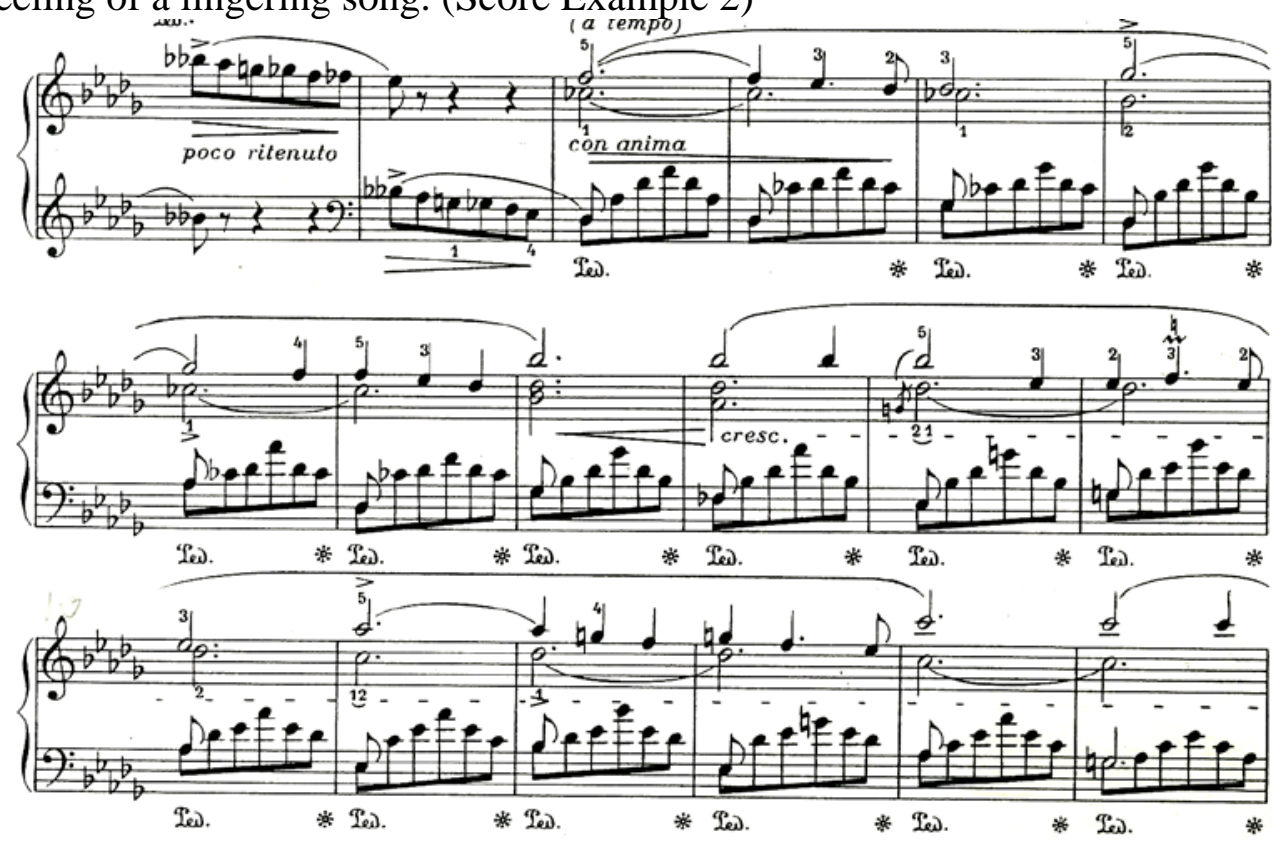

Score Example 2 63-80 bars

The second theme (con anima)(65-132 bars)has obvious melody features. The melody is exquisite and the rhythm is soothing and deep. The clever use of decorative sounds enhances the expressiveness of the music, combined with the intimacy of the close phrases, showing the composer's delusions for a better future. The handling of melody and accompaniment is a difficulty in the performance of this part. Players should pay attention to the intensity of the right hand melody is significantly greater than the accompaniment of the left eighths decomposition chords, and ensure the 
smooth and prominent melody part. While playing, beginners should keep the body relaxed and pour emotion on the fingertips to ensure that the tone is light and beautiful.(Score Example 3)

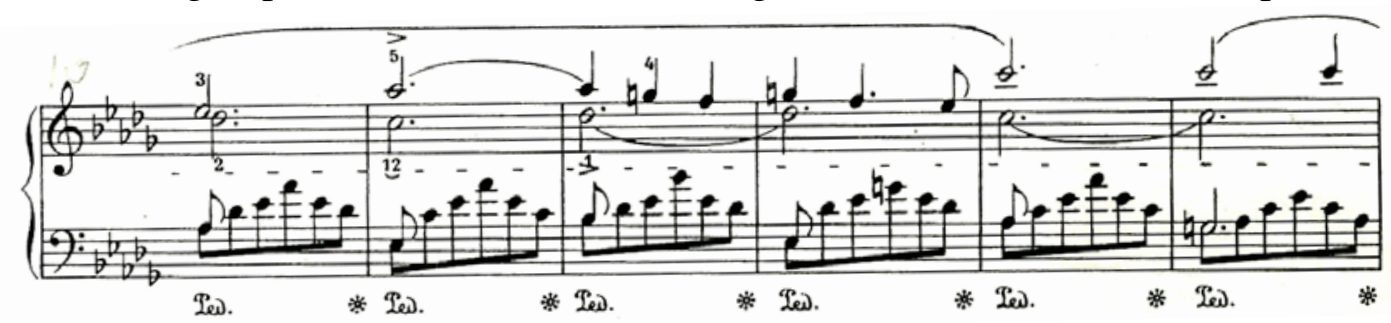

Score Example 3 75-80 bars

The end of the presentation section starts from the 118th bar, and the powerful short end is impressive. While playing, attention should be paid to the fluency and consistency of the large-span arpeggio sound playing and the close coordination of the two hands, to play the arpeggio down in one go.(Score Example 4)

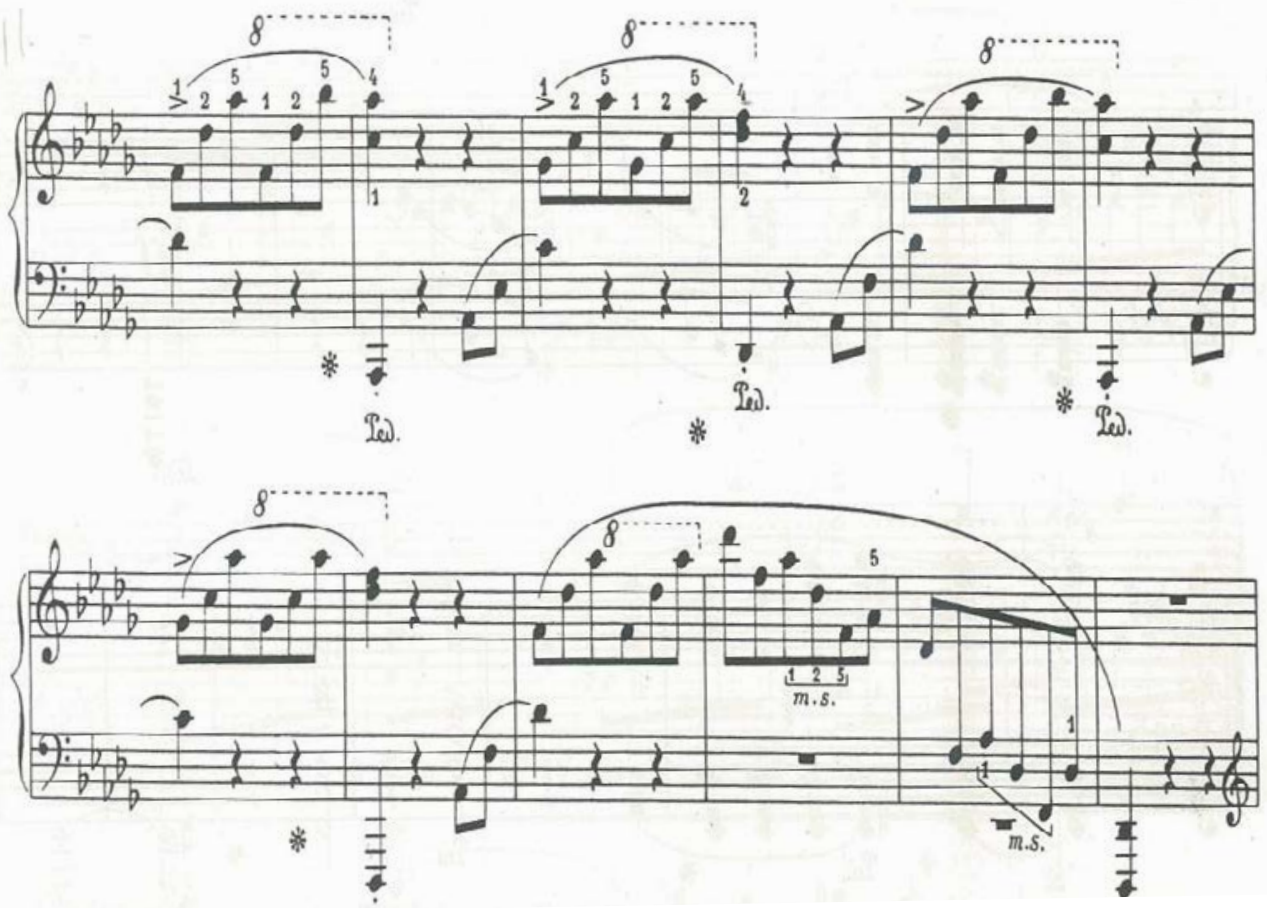

Score Example 4 118-129 bars

\section{Playing Skills in the Intermediate Section}

In The Second Scherzo in B-flat Minor,the Intermediate Section is the most unique part. It is separated from the previous Presentation Section and the following Reproduction Section by rests, with obvious independence, "leaving an impression of an independent movement in a divertimento."H·Lechttreet even called the Intermediate Section the interlude in the "Analysis of Chopin Piano Music". Players should pay enough attention to the Intermediate Section. The contrasting music images in this part of the music show a more intense emotional expression, requiring higher performance skills for the performers.

In stark contrast to the Presentation Section from the very beginning, the first theme(sotto voce)(265-309 bars) is soft and beautiful, after a sudden transition from the magnificent momentum at the end of the Presentation Section, with dramatic and unique charm. Each phrase at the beginning ends on the Ascendant $\mathrm{C}$, as if it leads us into the memory of past events. The singing melody is also memorable. The intensity of this part is the same as the beginning part of the music, which is also sotto voce, avoiding excessive playing volume. Afterwards, the performer must maintain the clarity 
of the vocal part, maintain a smooth horizontal melodic line when playing the chords, and appropriately control the intensity to create a noble and elegant musical atmosphere. It should be noted that the playing requirement of the 281th bar is delicatiss, so gentle and slender sounds are used to play this part. Pay attention to gradually slow down the speed while gradually reducing the volume to create a far-reaching, deep atmosphere and give the audience sufficient imagination space.(Score Example 5)
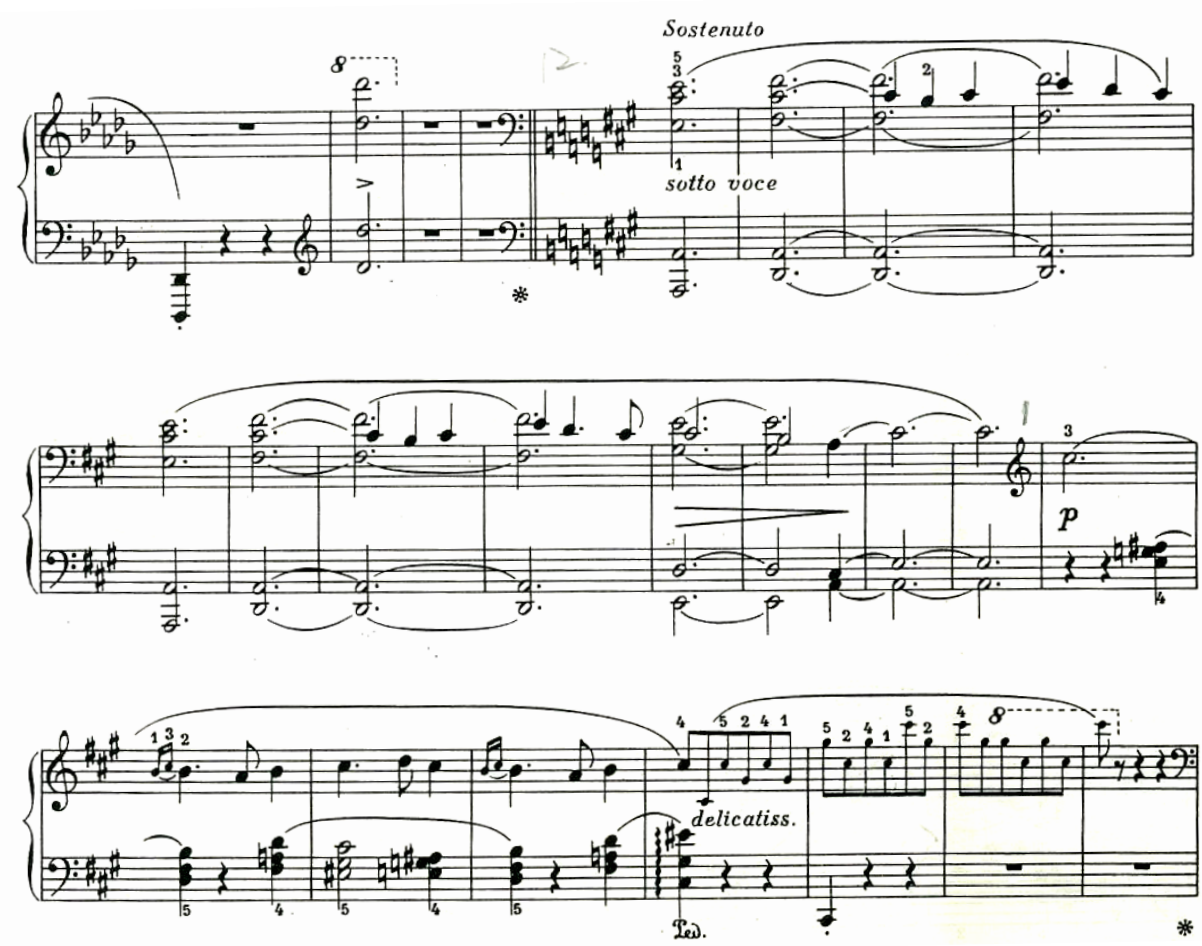

Score Example 5 261-284 bars

The second theme(express)(310-333 bars) is created with polyphony techniques and divided into four parts. The extensive application of polyphony techniques has made it more difficult to play the second part. When playing, pay attention to the clearness of the lines of each part. The combination of the two parts of the right hand is especially close. The tightness and the transition of the phrases should be handled properly to avoid unclear sounds.

It should be noted that the performer should pay enough attention to the playing skills of rubato in this section. Liszt once said, "Chopin first marked this technique in his own work, adding a special sign tempo rubato to his wonderful performance, with an easy-going and intermittent speed. The delicate rhythm is uneven and unstable, like a flag waving in the wind, or wheat ears that rise and fall in the gentle breeze, and the trees sway in the strong breeze."With regard to the treatment of rubato, it is imperative not to distort the original meaning of the music and to exaggerate it without authorization. The random speed or pause should be avoided as much as possible. Chopin believed that when playing, "the left hand is the conductor, tough and unyielding. It is a bell. The right hand can do what you want and can do." Mikuli thinks that "Chopin's rubato has an unshakable emotional logic, often proving its rationality through reinforced or diminished melodies, the details of the harmony and the structure of the sound pattern. The accompanying hand always follows strict beats, and The other hand that sings the melody frees the essence of music thinking from all the constraints of the rhythm." It can be seen that the key to playing rubato lies in the determination of proportions. It is imperative to perform the melody as a recitation on the basis of maintaining the original rhythm of the music. (See Score Example 6)

The third theme(Leggiero)(334-365 bars) has very distinctive melody, and the waltz-like rhythm seems to be the affectionate words of lovers, full of lovesickness. The arpeggio of the right hand should be clear and smooth, with just right force control, neither frivolous nor heavy. The half-decomposed chords of the left hand must be even and full, strongly setting off the melody of the 
right hand. (Score Example 6) The fixation of the fingering is the key to the arpeggio performance. The performer should pay special attention to the flexibility of the fingers and wrists. The wrist should always be soft and relaxed when hitting a key, and the finger must be attached to the wrist. The small rotation of the wrist controls the finger up and down to better enhance the playing speed.
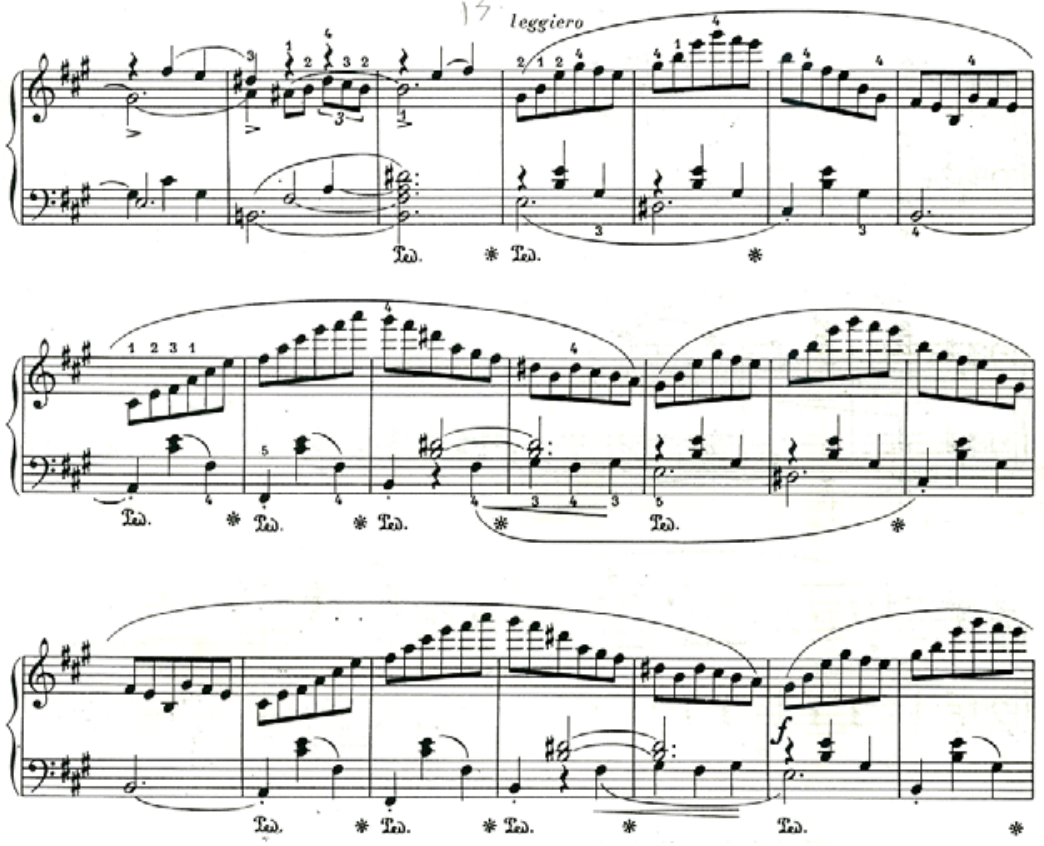

Score Example 6 331-344 bars

From the 366th bar, the composer quickly expanded the three themes, further increasing the difficulty of playing the music. Exciting melody and complex harmonies collide with each other. The audience's passion seemed to be ignited by the grand melody. The treatment of this part of the arpeggio should be first easy and then difficult, first slow and then fast. Beginners should relax their arms, let the tip of their fingers stand firmly, and eject each note independently and evenly. Try to arrange reasonable fingerings. Don't leave traces when changing fingers. Gradually speed up the playing speed in practice. When facing difficulties, summarize experience and practice repeatedly until the music is kept clear and exact in the high speed demanded by the track. Make sure that each note can be displayed in the player's hands. (Score Example 7)

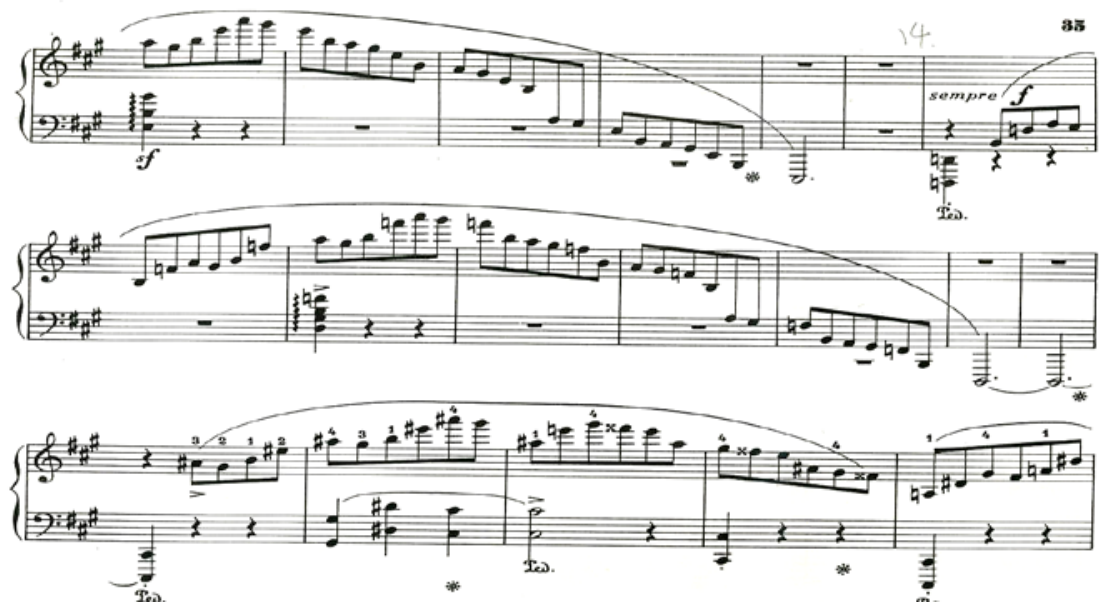

Score Example 7 462-480 bars

\section{Playing Skills in the Reproduction Section}

In the 12 bars from the beginning of 697th bar, the performer should pay attention to the coordination of the octave of the right hand and the amplitude of the left hand. How the volume and 
intensity of the two correspond to each other in the process of gradually becoming stronger and harmoniously is the focus for beginners to learn. Experience the focus. The performer must always keep relaxed arms and the strength of the palm joint in his performance. In addition, the fullness of emotions should be properly expressed, and the exaggerated strength and indecisiveness are undesirable. (See Score Example 8)

Chopin once said that musicians "should continuously study how to use pedals properly throughout their lives." In Chopin's works, the progression of harmonies, the progression of melody, and the structure of textures all require the player to use the pedals extensively. The fantastic sound effects created by using the pedals are indispensable for the perfect expression of the colors and feelings of music. In the Reproduction Section, the player should pay special attention to the use of the pedal. For example, a long span decomposed chord accompaniment pattern appears in the subject accompaniment part of the Reproduction Section. The performer should use a sustain pedal. The left-hand accompaniment must be played with the melody of the upper part and highlight the bass. In this way, the melody of the right-hand chord can be pushed forward step by step, and so can the music. (See Score Sample 8)

The Reproduction Section ends very suddenly and dramatically. The short arpeggios stopped suddenly at the volume of the ff, and end in a straightforward manner. The abruptly ended phrases are impressive, so people cannot help looking forward to the next part of the music. (Score Example 8)
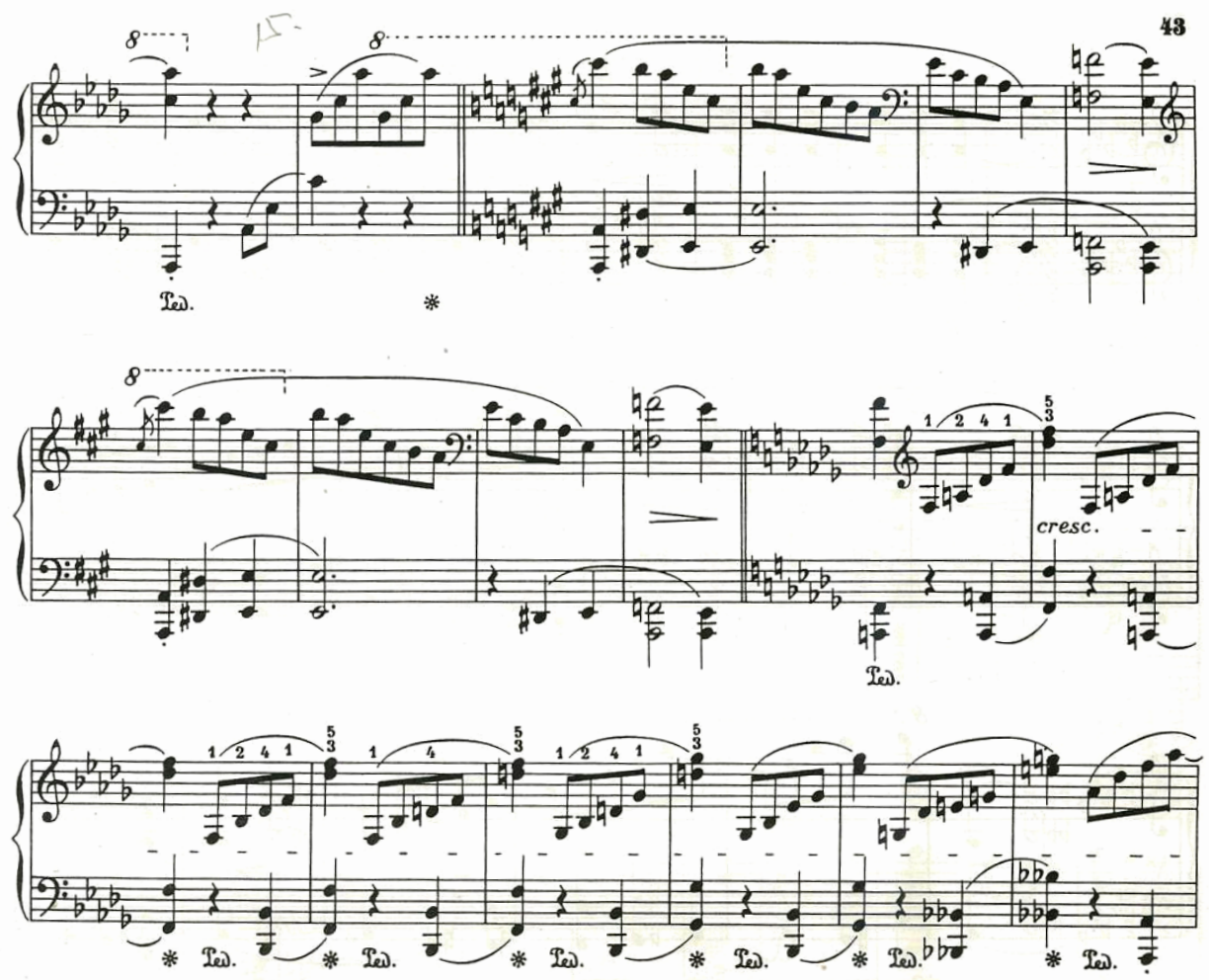

Score Example 8 814-831 bars

\section{Playing Skills in the Coda Section}

The Coda Section was tough and enthusiastic, and Chopin's creative skills are perfectly displayed in 65 bars. In the Coda Section, the composer adopted as many variations as possible, continuously shortening, repeating and modularizing, pushing the music into the field of free structure. The free structure of the Coda Section echoes with the regular structure of the beginning of the music, and the theatricality reaches its peak. Finally the music ends in the decisive chord, putting a perfect stop for The Second Scherzo in B-flat Minor. 
In terms of playing skills, the performer needs to pay attention to the gesture of the right hand. Only through enough exercises can the fast running sound pattern be better grasped. The finger should pay attention to the accuracy of touching and leaving the key. The sound should be smooth and clear, and always maintained close cooperation with the left hand octave. (See Score Example 8)

The 765th bars of The Second Scherzo in B-flat Minor is marked as sempre piumosso,Therefore, performers need to further accelerate their speed and increase their strength. The decisive, tough and enthusiastic momentum must be further strengthened. The end of the whole song should be clean and neat, instead of slowdown. The chords should be full and firm. After the chords, the arms and wrists should be immediately relaxed. Avoid rigid fingering and monotone sounds. (Score Example 9)
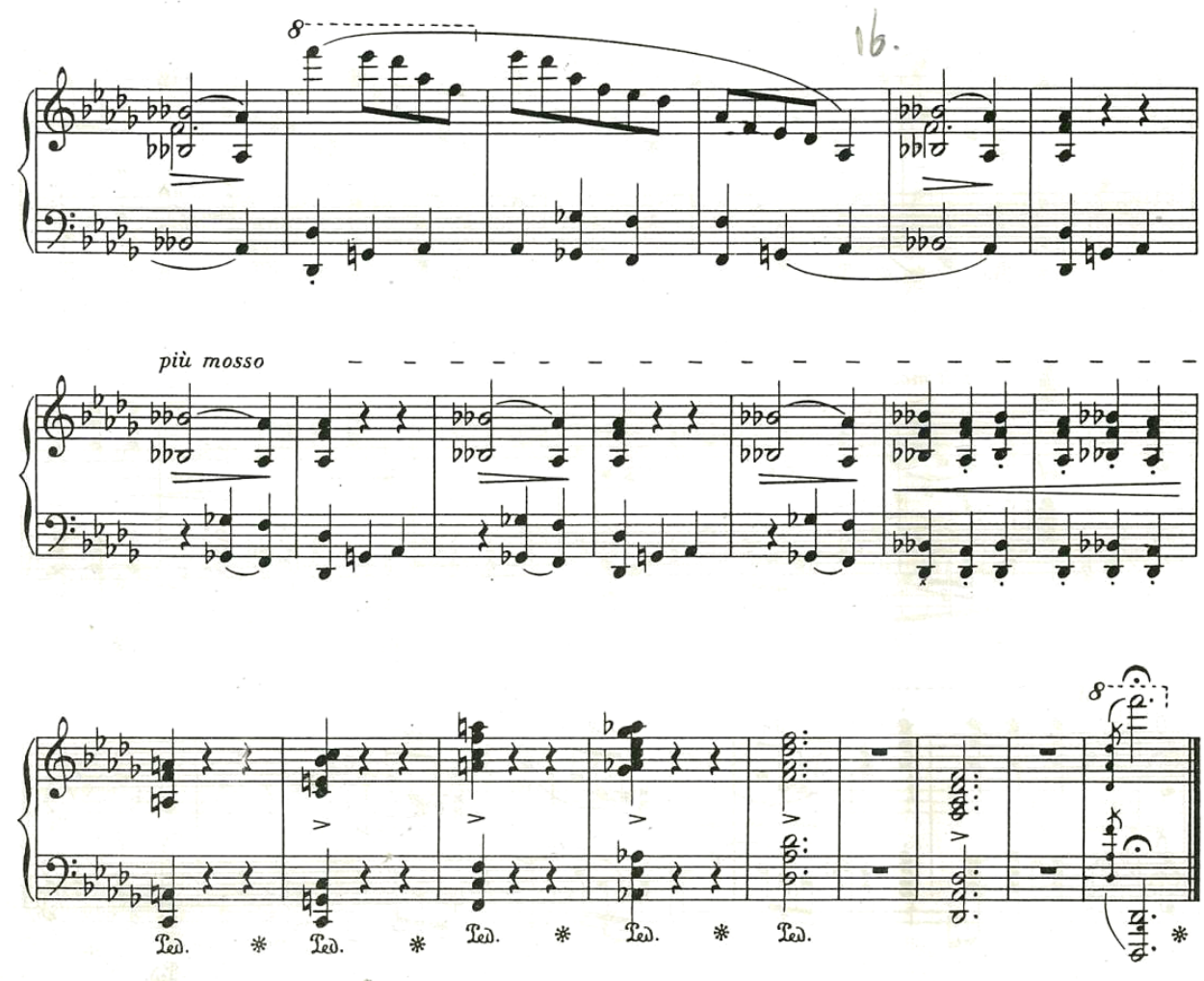

Score Example 9 859-880 bars

\section{Summary}

Chopin has made an indelible contribution to the development of piano music throughout the 19th century, creating a new era for piano music. As one of Chopin's masterpieces, The Second Scherzo in $B$-flat Minor shows the composer's near-unlimited creativity and superb compositional writing skills that deserves in-depth study for each performer. Due to the limitation of the level and time, this study on The Second Scherzo in B-flat Minor is inevitably biased. The author will further analyze and study Chopin's musical works in the future study and work, so as to better comprehend their unique artistic charm.

\section{References}

[1] Feng Zhiquan. Study on the large works of Chopin., Shanghai: Shanghai Conservatory of Music Press, 2007.

[2] Zhao Xiaosheng. Ways of Piano Performance, Shanghai: Shanghai World Book Publishing Company, 1999.

[3] Ye Jialiang. Analysis of Chopin's Piano Scherzos, Journal of Shaoxing College of Arts and Sciences, 2007, [6]. 
[4] Shen Xuan, Gu Wenxuan, Tao Xin. Compendium of Western Music History, Shanghai: Shanghai Music Publishing House, 1999.

[5] Zhang Leilei. A talk about the Creative Characteristics of Chopin's Scherzos, Music Life, 2007.

[6] Wu Zuqiang. Analysis of Musical Forms and Works, Beijing: People's Music Publishing House, 2003.

[7] Jiang Xiaosu. Chopin's Scherzos, Journal of Shandong Institute of Art, 2001, [2]. 